Original Research Article

\title{
Fluoxetine enhances maximal electroshock seizure threshold in Albino rat model when compared to phenytoin
}

\author{
Tanmoy Gangopadhyay ${ }^{1}$, Ananya Mandal ${ }^{1 *}$, Uma Shankar Keshri ${ }^{2}$
}

\begin{abstract}
${ }^{1}$ Department of Pharmacology, Bankura Sammilani Medical College, Bankura, West Bengal, India

${ }^{2}$ Department of Pharmacology, Rajendra Prasad Institute Medical Sciences, Ranchi, Jharkhand, India
\end{abstract}

Received: 01 November 2017 Accepted: 24 November 2017

\section{*Correspondence to: \\ Dr. Ananya Mandal, \\ Email: drananyamandal \\ @ gmail.com}

Copyright: (C) the author(s), publisher and licensee Medip Academy. This is an openaccess article distributed under the terms of the Creative Commons Attribution NonCommercial License, which permits unrestricted noncommercial use, distribution, and reproduction in any medium, provided the original work is properly cited.

\begin{abstract}
Background: Individuals with epilepsy have a higher incidence of psychiatric disorders than person without epilepsy. Epidemiological studies have shown that the co-morbidity of epilepsy and depression to be high as $50 \%$. The conventional anti-depressants are believed to lower the seizure threshold making it difficult to treat the co-morbid depression, but animal studies have shown SSRIs, a common anti-depressant, to have anti-convulsant properties. So, we propose to study the anticonvulsant effects of fluoxetine, a SSRI, in albino rats against maximal electroshock seizure and to compare against a standard antiepileptic drug phenytoin.

Methods: The anticonvulsant effect of fluoxetine was observed in model of maximal electroconvulsive seizure threshold in albino rats. The animals were divided into 3 groups having 6 animals each, receiving distilled water, fluoxetine and phenytoin respectively. The drugs were given orally, and the effect was observed on day 7, 14 and 21. Tonic hind-limb extension was taken as the parameter of electroshock seizure. The effects were compared against a standard anti-seizure drug phenytoin.

Results: Fluoxetine showed significant elevation of the seizure threshold following 14 days of administration ( $\mathrm{P}$ value 0.031 ). The effect was comparable to phenytoin with no significant difference after 7,14 and 21 days of treatment (P-value $0.485,0.699$ and 0.818 respectively) though phenytoin showed significant anti-seizure effect since day 7 of treatment.

Conclusions: Fluoxetine showed significant anti-seizure activity against electroconvulsive seizure in albino rats.
\end{abstract}

Keywords: Anticonvulsant, Albino rats, Fluoxetine, Maximal electroshock seizure, Phenytoin

\section{INTRODUCTION}

Epilepsy, one of the oldest neurological diseases known to mankind, describes a condition where a person has recurrent seizures due to a chronic underlying process. Apart from affecting a large population worldwide it can co-exist with a variety of psychiatric disorders depression being the commonest with co-morbidity as high as $60 \% .^{1,2}$ Unfortunately many conventional antidepressants show epileptogenic potential making it difficult to treat the coexisting depression in patients with epilepsy. However,
SSRIs, one of the most widely used class of antidepressants seem to be relatively safe in this regard..$^{3,4}$ They, in fact have shown anticonvulsant action in some animal models of epilepsy though some uncontrolled clinical case studies have shown them to increase seizure frequency in patients with depression. ${ }^{5}$

Another major drawback of the commonly used anticonvulsants is the adverse reactions encountered during chronic use. The propensity of the adverse effects increases with the uses of a combination of 
anticonvulsants. It may be beneficial to explore some new combinations those may allow dose reduction of the conventional antiepileptics and thus reducing the adverse effects without affecting the seizure control.

The purpose of the present study is to ascertain the anticonvulsant action of Fluoxetine, a commonly prescribed SSRI in threshold of maximal electroconvulsant model on albino rats and to compare that with the anticonvulsant effect of phenytoin sodium alone and in combination with fluoxetine.

\section{METHODS}

The study was done in the Department of Pharmacology and Therapeutics, in a tertiary medical college. Approval of the Institutional Ethics committee was obtained prior to the study.

Healthy, adult, albino rats of either sex weighing about 150-200gms were used in the study. The animals were kept in separate cages with natural light/dark cycle and provided with free access to food and water. All the animals were given same kind of food and tap water. One week was given to the animals for acclimatization and adjustment to the new environment. Standard laboratory conditions of temperature, humidity and aeration were maintained.

An electro-convulsiometer was used. Strength of current was $30 \mathrm{~mA}$ and duration was 0.3 seconds. Ear clip electrodes were used instead of corneal electrodes to minimize animal suffering.

The animals were weighed with the balance. They all were kept in individual cages with numbers marked on the side of the cage. Free access to food and water was given except during the time of experiment. The floor of the cages was covered with grain husk which was cleaned every second day. The animals were inspected frequently to rule out any infection.

The animals were acclimatized to the feel of ear clip electrodes, so that they do not resist unduly during administration of electric shock, because stress alters the seizure threshold.

At first the threshold for electro-convulsion was determined. The ears were cleaned with spirit to remove the sebaceous gland secretions, and then with saline for better electrical conduction. Electric shock was given starting from $30 \mathrm{~mA}$ and increasing up to $60 \mathrm{~mA}$.The strength of current causing tonic hind limb extension of $\geq 90^{\circ}$ was taken as seizure threshold current(STC). Those animals who did not show hind limb extension even at $60 \mathrm{~mA}$ current were discarded.

The animals then were randomly divided into control, fluoxetine, phenytoin; each group containing six animals. Rats in control group received distilled water while the rats in fluoxetine group received fluoxetine suspension orally in a dose of $10 \mathrm{mg} / \mathrm{kg}$ body weight. The drug was diluted in distilled water to the concentration of $1 \mathrm{mg} / \mathrm{ml}$. Phenytoin sodium (Tab Eptoin) was given to the third group orally in a dose of $20 \mathrm{mg} / \mathrm{kg}$ dissolved in distilled water to get a concentration of $2 \mathrm{mg} / \mathrm{ml}$. After giving the drugs for 7 days the rats were again exposed to electric current and their threshold for hind limb extension were noted. The drugs were continued with the same dose and the threshold of hind limb extension was noted on day 7 , day 21 and day 28 .

\section{RESULTS}

All the obtained data were noted down and processed for statistical analysis. The results were expressed in mean seizure threshold and standard deviations. We performed Kolmogorov-Smirnov test and Shapiro-Wilk test to find the normalcy in the distribution of data and found that the data was non-parametric in distribution. Hence for subsequent analysis, non-parametric test was done, i.e. for determination of between groups variation, KruskalWallis test was done and for within-group variation estimation, Friedman's ANOVA was done. At baseline all the groups were comparable and there was no significant difference between groups as evident from the Kruskal Wallis $P$ value 0.7691

Table 1: Changes in mean threshold values in groups receiving distilled water (DW), phenytoin (P)and fluoxetine (F) respectively in comparison to the baseline after 7, 14 and 21 days of treatment.

\begin{tabular}{|c|c|c|c|c|}
\hline & \multicolumn{3}{|c|}{ Men Threshold Value (mA) } & \multirow{2}{*}{$\begin{array}{l}\text { P value } \\
\text { (Kruskal Wallis) }\end{array}$} \\
\hline & Control & Standard & Test & \\
\hline Baseline & $45 \pm 13.42$ (DW1) & $42.50 \pm 11.29(\mathrm{P} 1)$ & $40.00 \pm 12.25(\mathrm{~F} 1)$ & 0.7691 \\
\hline After 7 days & $42.50 \pm 11.29$ (DW2) & $60.00 \pm 9.49(\mathrm{P} 2)$ & $55.00 \pm 7.75(\mathrm{~F} 2)$ & 0.0330 (DW2 vs P2) \\
\hline After 14 days & $37.50 \pm 8.22(\mathrm{DW} 3)$ & $62.50 \pm 11.29(\mathrm{P} 3)$ & $60.00 \pm 9.49(\mathrm{~F} 3)$ & $\begin{array}{l}0.0051 \text { (DW3 vs P3 and } \\
\text { DW3 vs F3) }\end{array}$ \\
\hline After 21 days & $35.00 \pm 7.75(\mathrm{DW} 4)$ & $62.50 \pm 11.29(\mathrm{P} 4)$ & $65.00 \pm 7.75(\mathrm{~F} 4)$ & 0.0028 (D vs $\mathrm{P}$ and $\mathrm{D}$ vs $\mathrm{F})$ \\
\hline $\begin{array}{l}\text { P value (Freidman's } \\
\text { ANOVA) }\end{array}$ & Not Significant & $\begin{array}{l}<0.0001 \text { (P1 vs } \mathrm{P} 3 \\
\text { P1 vs P4) }\end{array}$ & 0.0004 (F1 vs F4) & \\
\hline
\end{tabular}


After 7 days of treatment, Kruskal Wallis test between groups showed significant difference (P value 0.0330 ). We did Dunn's Multiple comparison test to find between which values the difference lies and found there is significant difference between DW2 and P2 i.e. between the groups receiving distilled water and phenytoin. But no difference was found between other groups.

After 14 days of treatment the Kruskal Wallis P value was 0.0051(significant) and the difference were between groups receiving distilled water and phenytoin as well between the groups receiving distilled water and fluoxetine. The same pattern continued after 21 days and this time the $\mathrm{P}$ value was 0.0028 . For within-group comparison we did Friedman's ANOVA followed by Dunn's multiple comparison test to locate the exact area of difference. We found no significant difference in the group receiving distilled water but the groups receiving phenytoin showed significant difference from the baseline after 14 and 21 days of treatment. The groups receiving fluoxetine did not show any significant difference from baseline after 7 and 14 days but after 21 days of treatment significant elevation of seizure threshold from the baseline was found ( $\mathrm{P}$ value 0.0004). The differences between groups are shown in Table 1.

\section{DISCUSSION}

In present study, we induced maximal electroshock seizure in three groups of albino rats receiving distilled water, phenytoin and fluoxetine respectively and compared the effects of those drugs on the mean seizure threshold after 7, 14 and 21 days of treatment. We found that fluoxetine, a commonly prescribed anti-depressant has the potential to significantly increase the mean seizure threshold of Maximal electroshock seizure in albino rats after 14 days of treatment in comparison to baseline. The effect was not different from a standard anticonvulsant phenytoin.

Epilepsy is a heterogeneous disorder with diverse neurological manifestations. The basic underlying mechanism of epilepsy is hypersynchronous discharges of a group of neurons due to abnormal ionic conductance or an imbalance in the excitatory and inhibitory neurotransmitters. Depression on the other hand is thought to be caused by derangement of various neurotransmitters among them serotonin is one of the most prominent. Serotonin has also vital roles to play in the process of audiogenically, chemically or electrically induced seizures. The role of serotonin on seizures was first described by Bonycastle et al. ${ }^{6}$ They showed that various anticonvulsants raised the serotonin levels in brain. On the other hand depletion of serotonin lowers the seizure threshold. ${ }^{7}$ Several different types of serotonergic receptors $\left(5 \mathrm{HT}_{1 \mathrm{~A}}, 5 \mathrm{HT}_{1 \mathrm{~B}}, 5 \mathrm{HT}_{2 \mathrm{~A}}, 5 \mathrm{HT}_{2 \mathrm{C}}, 5 \mathrm{HT}_{7}\right)$ present in the cortex and hippocampus especially on glutaminergic or GABAergic neurons may influence neuronal excitability. ${ }^{8}$ Activation of $5-\mathrm{HT}_{1 \mathrm{~A}}$ post synaptic receptors in the hippocampus elicits a membrane hyperpolarizing response related to increased potassium conductance. ${ }^{9,10} 5$-HT also inhibits low $\mathrm{Mg}^{2+}$-induced epileptiform activity, by reducing excitatory postsynaptic potentials, mediated by $\mathrm{N}$-methyl-d-aspartate (NMDA) in the subiculum and entorhinal cortex. ${ }^{11,12}$ Serotonin thus may contribute to epilepsy along with depression. Epilepsy may be associated with co-existent depression and it is necessary to treat depression in patients suffering from epilepsy.

Fluoxetine is a selective serotonin reuptake inhibitor that is used to treat depression along with other conditions like anxiety, bulimia, OCD, panic disorders etc. In present study we have observed the effect of fluoxetine on the maximal electroshock seizure threshold in albino rats and compared it with a standard anti-seizure drug phenytoin. We have found significant elevation of the seizure threshold in animals treated with fluoxetine and the effects were comparable to that of phenytoin.

A study done by Renula Marwah et al on the effect of fluoxetine on ICES in albino mice showed similar results but the effects were evident from day 7 where we found significant change from day 14 onwards. ${ }^{13}$ In a different study Kinga K. Borowic et al found that Fluoxetine in doses up to $20 \mathrm{mg} / \mathrm{kg}$ failed to affect the electroconvulsive threshold but it enhances the antiepileptic properties of other anticonvulsants. ${ }^{14}$ In another study Danka Peričić et al showed that anti-seizure role of fluoxetine in picrotoxin induced seizure model. ${ }^{15}$ Dailey $\mathrm{J}$ W et al has shown the protective role of Fluoxetine in sound induced seizures in genetically epilepsy prone rats. ${ }^{16}$ Mutant mice lacking the $5-\mathrm{HT}_{2 \mathrm{C}}$ receptor subtype show high susceptibility to audiogenic seizures, indicating that serotonergic stimulation of $5-\mathrm{HT}_{2 \mathrm{C}}$ receptors suppresses neuronal hyperexcitability and seizure activity. ${ }^{17-19}$ E Favale et al in an open-label study on humans, has shown anti-seizure effect of fluoxetine. ${ }^{20}$ In present study we found that though at the baseline and after day 7 there is no significant difference between the groups receiving distilled water and fluoxetine, after $14^{\text {th }}$ day there is significant elevation of the seizure threshold in the group receiving fluoxetine which is continued in day 21. Phenytoin showed significant elevation in the seizure threshold since day 7 but there is no significant difference between the groups receiving phenytoin and fluoxetine.

So, we can see that the anticonvulsant effect observed with fluoxetine is in agreement with various other studies conducted on different animal models of epilepsy. As seizure control is achieved in many patients at the cost of several distressing and limiting side effects, there is a need of development of newer antiepileptic drugs. Newer targets should be explored also for better understanding and better outcome of seizure treatment. The role of serotonin in seizures is now being evaluated and extensively researched. As there is also associated depression in many cases of epilepsy and vice-versa, the role of a drug which can be useful in both cases cannot be overemphasized. So, Fluoxetine can be an option in patients of epilepsy with or without depression, but there is need of further clinical research in this area. 


\section{ACKNOWLEDGEMENTS}

Author would like to thank Dr. Sourav Chakraborty, Dr. Ratul Banerjee and members of the Department of Pharmacology Bankura Sammilani Medical College, Bankura \& RIMS, Ranchi.

Funding: No funding sources

Conflict of interest: None declared

Ethical approval: The study was approved by the Institutional Ethics Committee

\section{REFERENCES}

1. Ebert U. Basic mechanism of psychotropic drugs. Epilepsia. 2002;43:2-7.

2. Gross R, Dannon P, Lepkifker E, Zohar J, Kotler M. Generalized seizures caused by fluoxetine overdose. Am J Emerg Med. 1998;3:328-30.

3. Skowron DM, Stimmel GL. Antidepressants and the risk of seizures. Pharmacoth. 1992;12:18-22.

4. Jobe PC, Browning RA. The serotonergic and noradrenergic effects of antidepressant drugs are anticonvulsant, not proconvulsant. Epilepsy Behav. 2005;7:602-19.

5. Bagdy G, Kecskemeti V, Riba P, Jakus R. Serotonin and epilepsy. J Neurochem. 2007;100:857-73.

6. Bonnycastle DD, Giarman NJ and Paasonen MK. Anticonvulsant compounds and 5-hydroxytryptamine in rat brain. Br J Pharmacol. 1957;12:228-31.

7. Browning RA, Wood AV, Merrill MA, Dailey JW, Jobe PC. Enhancement of the anticonvulsant effect of fluoxetinefollowing blockade of 5-HT1A receptors. Eur. J. Pharmacol 1997;336:1-6.

8. Barnes NM, Sharp T. A review of central 5-HT receptors and their function. Neuropharmacol. 1998;38:1083-152.

9. Hesdorffer DC, Hauser WA, Annegers JF, Cascino G. Major depression is a risk factor for seizures in older adults. Ann Neurol. 2000;47:246-9.

10. Nemeroff CB, Owens MJ. Treatment of mood disorders. Nat Neurosci. 2002;5:1068-70.

11. Behr J, Heinemann U. Effects of serotonin on different patterns of low $\mathrm{Mg}^{2+}$-induced epileptiform activity in the subiculum of rats studied in vitro. Brain Res. 1996;737:331-4.

12. Schmitz D, Empson RM, Gloveli T, Heinemann U. Serotonin blocks different patterns of low $\mathrm{Mg}^{2+}$ induced epileptiform activity in rat entorhinal cortex, but not hippocampus. Neurosci. 1997;76:449-58.

13. Marwah R, Pal SN, Pillai KK. Effect of fluoxetine on increasing-current electrochock seizures (ICES) in mice. Indian J Pharmacol. 1999;31:350-3.

14. Borowicz KK, Stepień K, Czuczwar SJ. Fluoxetine enhances the anticonvulsant effects of conventional antiepileptic drugs in maximal electroshock seizures in mice. Pharmacol Rep. 2006;58:83-90.

15. Peričić D, Lazić J, Jembrek J, Maja SS. Stimulation of 5-HT1A receptors increases the seizure threshold for picrotoxin in mice. Eur J Pharmacol. 2005;527:10510.

16. Yan QS, Jobe PC, Cheong JH, Ko KH, Dailey JW. Role of serotonin in the anticonvulsant effect of fluoxetine in genetically epilepsy-prone rats. Arch Pharmacol. 1994;350(2):149-52.

17. Tecott LH, Sun LM, Akana SF, Strack AM, Lowenstein DH, Dallman MF, et al. Eating disorder and epilepsy in mice lacking $5-\mathrm{HT}_{2 \mathrm{C}}$ serotonin receptors. Nat. 1995;374:542-6.

18. Brennan TJ, Seeley WW, Kilgard M, Schreiner CE, Tecott LH. Sound-induced seizures in serotonin 5$\mathrm{HT}_{2 \mathrm{C}}$ receptor mutant mice. Nat Genet. 1997;16:38790.

19. Applegate CD, Tecott LH. Global increases in seizure susceptibility in mice lacking $5-\mathrm{HT}_{2 \mathrm{C}}$ receptors: a behavioral analysis. Exp Neurol. 1998;154:522-30.

20. Favale E, Rubino V, Mainardi P, Lunardi G, Albano C. Anticonvulsant effect of fluoxetine in humans Neurol. 1995;45:1926-7.

Cite this article as: Gangopadhyay T, Mandal A, Keshri US. Fluoxetine enhances maximal electroshock seizure threshold in Albino rat model when compared to phenytoin. Int J Basic Clin Pharmacol 2018;7:138-41. 